Volume 24 No 2 Tahun $2020 \mid 52$

\title{
ANALISIS PENINGKATAN MINAT BELI PADA RESTORAN SE'I SAPI LAMALERA MELALUI VARIABEL ELECTRONIC WORD OF MOUTH DAN CITRA MEREK PADA MAHASISWA INSTITUT TEKNOLOGI HARAPAN BANGSA
}

\author{
Rierie Andriani Larastanio \\ Departemen Manajemen, Sekolah Tinggi Ilmu Ekonomi Harapan Bangsa \\ Laura Lahindah \\ Departeman Manajemen, Sekolah Tinggi Ilmu Ekonomi Harapan Bangsa
}

\begin{abstract}
The rapid increase of the culinary business in the city of Bandung has caused culinary businessmen to have a competitive advantage to continue to survive in this business. Every part of this sector is used to allow it. This study aims to determine how many influences of e-WOM on brand image and performance on purchase intention. The object in this study was Se'i Sapi Lamalera. This study was conducted on 307 respondents using a quantitative descriptive approach. Therefore, data analysis is in the form of statistical analysis in the form of SEM-PLS. There is data processing using the Smart-Partial Least Square (Smart-PLS) version 3.0. PLS (Partial Least Square). The results of this study indicate that based on $t$ test, $e$-WOM and brand image have a positive and significant effect on purchase intention in Se'i Sapi Lamalera and e-WOM has a positive and significant effect on purchase intention in Se'i Sapi Lamalera.
\end{abstract}

Keywords: $e-W O M$, Brand image, Purchase intention

\begin{abstract}
ABSTRAK
Peningkatan bisnis kuliner di kota Bandung yang sangat pesat menyebabkan pelaku bisnis di sektor usaha ini dituntut untuk memiliki keunggulan kompetitif untuk terus bertahan di bisnis ini. Penelitian ini bertujuan untuk mengetahui seberapa besar pengaruh $e$-WOM terhadap citra merek serta dampaknya pada minat beli. Objek dalam penelitian ini adalah Se'i Sapi Lamalera. Penelitian ini dilakukan pada 307 responden dengan menggunakan pendekatan deskriptif kuantitatif. Teknik analisis data dilakukan dengan menggunakan SEM-PLS. Hasil penelitian ini menunjukkan bahwa $e$ WOM dan citra merek berpengaruh secara positif terhadap minat beli di Se'i Sapi Lamalera sedangkan $e$-WOM berpengaruh secara positif terhadap minat beli di Se'i Sapi Lamalera.
\end{abstract}

Kata Kunci: $e-W O M$, Citra Merek, Minat Beli

\section{PENDAHULUAN}

Kota Bandung adalah salah satu kota yang ditetapkan sebagai kota wisata kuliner nasional oleh Kementerian Pariwisata Republik Indonesia pada tahun 2017. Penetapan Kota Bandung sebagai kota wisata kuliner nasional membuat para pelaku bisnis melihat kesempatan yang besar dalam sektor usaha ini. Perkembangan bisnis kuliner di Kota Bandung pun setiap tahunnya mengalami peningkatan. Peningkatan tersebut mengindikasikan persaingan di sektor ini yang semakin ketat. 


\section{3 | Bina Ekonomi}

Peningkatan jumlah restoran atau rumah makan ini diprediksi akan terus meningkat, sehingga penting bagi pelaku usaha di sektor ini untuk selalu berinovasi dan menerapkan strategi pemasaran yang baik untuk terus bertahan di sektor usaha ini.

Sertifikat halal menjadi salah satu strategi yang biasa digunakan oleh pengusaha kuliner dalam memenangkan kompetisi. Hal ini sejalan dengan anjuran dari pemerintah Kota Bandung melalui Dinas Koperasi dan Usaha Kecil Menengah, Industri, dan Perdagangan (KUKM-indag) yang menghimbau seluruh restoran atau rumah makan di Kota Bandung untuk memiliki sertifikat halal (Hong, 2016). Kepala Dinas KUKM-indag mengatakan bahwa sertifikasi halal juga merupakan salah satu fasilitas untuk memberikan jaminan kepada wisatawan muslim. Selain itu Dinas KUKM-indag menargetkan pada tahun 2017, Kota Bandung masuk sebagai kota halal (GoMuslim, 2016). Dengan adanya imbauan yang diberitahukan oleh Dinas KUKM-indag tersebut membuat para pelaku di sektor usaha kuliner mulai mengetahui pentingnya sertifikasi halal dan mulai melakukan serangkaian proses untuk mendapatkan sertifikat halal dari LPPOM MUI.

Salah satu restoran atau rumah makan di Kota Bandung adalah Se'i Sapi Lamalera. Se'i Sapi Lamalera ini adalah rumah makan yang menawarkan kuliner khas Nusa Tenggara Timur, dengan "Se'i" sebagai menu utamanya. Restoran ini memiliki keunggulan kompetitifnya dengan mengganti bahan bakunya. Di daerah asalnya, "Se'i" berbahan baku daging babi, namun Se'i Sapi Lamalera mengganti bahan baku daging babi menjadi bahan baku daging sapi. Sehingga Se'i Sapi Lamalera dapat menciptakan citra rumah makan atau restoran halal.

Menurut Kotler dan Keller (2012), bahwa dalam tahap evaluasi proses keputusan pembelian, konsumen membentuk kesukaan atau minat atas merek-merek dalam sekumpulan pilihan-pilihan, konsumen juga mungkin membentuk minat beli produk yang paling disukai. Minat beli menurut Kotler dan Keller (2012) adalah perilaku pelanggan yang muncul sebagai respon terhadap objek yang menunjukkan keinginan pelanggan untuk melakukan pembelian. Minat beli adalah pengaruh atau rekomendasi baik secara individu maupun kelompok terhadap suatu produk atau jasa yang bertujuan untuk memberikan informasi secara personal yang dalam proses komunikasinya dari mulut ke mulut atau sering disebut sebagai Word of Mouth (WOM). Seiring berkembangnya era digital WOM pun mulai bergeser dan menjadi $e$-WOM. Tidak seperti WOM, e-WOM memiliki jangkauan yang lebih luas. Kamtarin (2012) mengemukakan bahwa penyebaran informasi melalui $e$-WOM dilakukan melalui media online atau internet seperti melalui email, blog, chat room, facebook, twitter dan berbagai jenis media sosial lainnya yang bisa menimbulkan interaksi antara konsumen satu dengan konsumen lainnya, dengan adanya komunikasi sosial secara online ini akan secara otomatis bisa membantu konsumen berbagi pengalaman tentang produk atau jasa yang mereka peroleh dalam melakukan proses pembelian. Dengan membaca atau mendengar pendapat seseorang terhadap suatu produk atau jasa, dapat membangun pandangan atau persepsi terhadap produk atau jasa tersebut, sehingga adanya $e$-WOM berpengaruh terhadap citra merek minat beli konsumen

Electronic Word of Mouth (e-WOM) menurut Thurau et al. (2004) merupakan bentuk komunikasi pemasaran yang berisi tentang pernyataan positif atau negatif yang dilakukan pelanggan potensial, pelanggan maupun mantan pelanggan tentang suatu produk atau perusahaan, yang tersedia bagi banyak orang atau lembaga melalui media Internet. Sedangkan menurut Kotler dan Keller (2012) citra merek (brand image) didefinisikan sebagai persepsi dan keyakinan yang dipegang oleh konsumen, sebagaimana tercermin dalam asosiasi yang disimpan dalam ingatan konsumen. Hal 
ini dapat diartikan sebagai persepsi dan kepercayaan yang dipegang oleh konsumen, yang tercermin atau melekat dalam benak dan memori dari seorang konsumen sendiri. Persepsi ini dapat terbentuk dari informasi atau pengalaman masa lalu konsumen terhadap merek tersebut.

Salah satu platform media sosial dengan jumlah pengguna aktif terbanyak di Indonesia adalah Instagram. Melihat adanya peluang dalam memasarkan produk dan untuk lebih mudah menjangkau konsumen dengan mudah, Se'i Sapi Lamalera pun turut aktif dalam platform media sosial tersebut. Untuk mengendalikan e-WOM terhadap usahanya, Se'i Sapi Lamalera mulai aktif menyampaikan berita-berita dengan membuat banyak konten tentang Se'i Sapi Lamalera, menjawab komentar dari para audience dan followers di media sosial instagram, baik itu komentar positif maupun negatif. Se'i Sapi Lamalera ingin menunjukkan citra yang ramah di mata konsumennya. Sehingga akan menimbulkan komentar yang cenderung positif terhadap Se'i Sapi Lamalera itu sendiri dengan tujuan agar tercipta citra merek yang positif dan menaikkan minat beli konsumen. Hal ini sejalan dengan penelitian Samuel dan Lianto (2014) yang menunjukkan bahwa $e$-WOM terbukti berpengaruh positif terhadap citra merek dan minat beli.

Berdasarkan pada gambar 1. dapat dilihat bahwa jumlah transaksi di Se'i Sapi Lamalera setelah pengelolaan Instagram Se'i Sapi Lamalera dilakukan terus menerus mengalami peningkatan. Peningkatan ini menunjukkan adanya peningkatan jumlah transaksi dan penjualan di Se'i Sapi Lamalera yang berarti tingginya minat beli di rumah makan ini. Sehingga penelitian ini bertujuan untuk mengetahui apakah e-WOM mempengaruhi citra merek dan minat beli pada Se'i Sapi Lamalera, serta apakah e-WOM mempengaruhi minat beli melalui citra merek pada Se'i Sapi Lamalera.

Berikut data yang menunjukkan peningkatan penjualan pada Se'i Sapi Lamalera dari bulan Agustus 2017 hingga Juli 2018, adalah sebagai berikut:

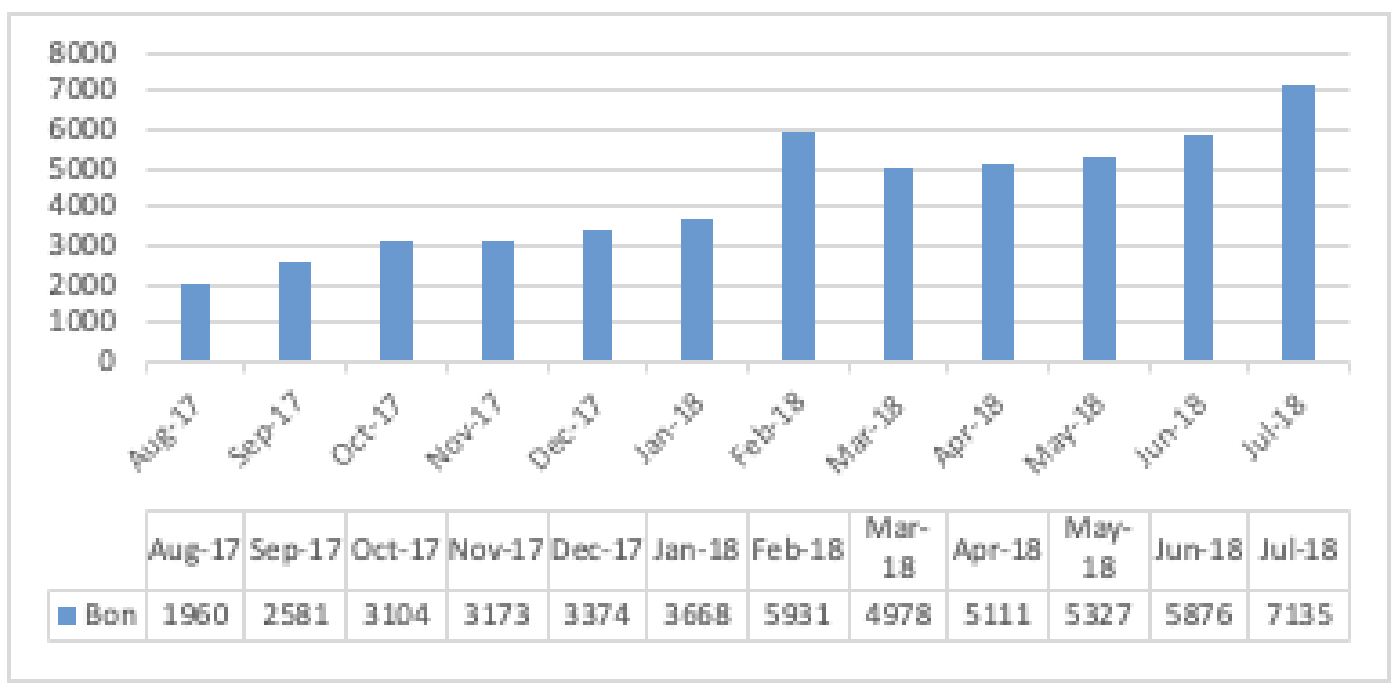

Gambar 1. Jumlah Bon Transaksi Penjualan di Se'i Sapi Lamalera 2017-2018

Sumber : Se'i Sapi Lamalera (2018)

\section{METODE DAN DATA}

Dalam penelitian ini, yang menjadi objek penelitian adalah pengunjung rumah makan Se'i Sapi Lamalera Bandung. Penelitian ini menggunakan metode analisis kausal, yaitu analisis yang mencari 
hubungan bersifat sebab akibat, untuk mengetahui faktor apa saja yang mempengaruhi meningkatnya minat beli pada Se'i Sapi Lamalera.

Populasi dalam penelitian ini adalah mahasiswa Institut Teknologi Harapan Bangsa Bandung, dan untuk penentuan sampel, peneliti menggunakan teknik purposive sampling dan untuk menentukan jumlah sampel, peneliti menggunakan rumus slovin dengan taraf signifikan 0.05 atau 5\% dan didapati 307 sampel yang akan digunakan dalam penelitian ini. Sampel yang diambil dalam penelitian ini memiliki kriteria sebagai berikut :

1. Mengetahui rumah makan Se'i Sapi Lamalera

2. Belum pernah melakukan transaksi pada produk yang ditawarkan di rumah makan Se'i Sapi Lamalera.

Teknik pengumpulan data dalam penelitian ini dilakukan melalui dua cara, yaitu penelitian kepustakaan dan penelitian lapangan. Penelitian kepustakaan dilakukan untuk mengumpulkan data mengenai teori-teori yang mendukung penelitian dan data pendukung lainnya, sedangkan penelitian lapangan dilakukan dengan menggunakan angket atau kuesioner sesuai dengan kriteria yang telah dibuat sebelumnya. Teknis analisis data dilakukan dengan menggunakan Structural Equation Modeling (SEM) dengan metode Partial Least Square (PLS). Alat analisis data menggunakan WARP PLS.

\section{PEMBAHASAN}

\subsection{Model penelitian}

Analisis data dilakukan dengan diawali dengan pengumpulan data. Data yang dikumpulkan menggunakan skala likert. Setiap jawaban diberi skor berupa angka dengan bobot 1 sampai 5. Hasil analisis deskriptif responden menunjukkan dari 307 responden terdapat 147 atau $47.9 \%$ berjenis kelamin laki-laki, sedangkan 160 atau sebanyak 52.1\% berjenis kelamin perempuan. Responden dalam penelitian ini berada pada kelompok usia 21 - 30 tahun merupakan responden yang paling tinggi jumlahnya yaitu sebanyak 215 atau sebesar 70.0\%, sedangkan kelompok usia $<21$ tahun (dibawah usia dua puluh satu tahun) sebanyak 92 responden atau sebesar $30.0 \%$.

Pengolahan data menggunakan Warp, PLS, dengan Langkah-langkah sebagai berikut: evaluasi outer model, uji inner model, dan uji hipotesis.

\subsection{Evaluasi Measurement (Outer Model)}

Dalam evaluasi measurement (outer model) terdapat 4 uji, diantaranya adalah Confergent Validity, Discriminant Validity, Average Variance Extracted, Composite Reliability dan Cronbach Alpha

Pengujian Convergent Validity dari masing-masing indikator konstruk. Menurut Chin dalam Ghozali (2014), suatu indikator dikatakan mempunyai validitas yang baik jika nilainya lebih besar dari 0,70, sedangkan loading factor 0,50 sampai 0,60 dapat dianggap cukup. Berdasarkan kriteria ini bila ada loading factor dibawah 0,50 maka akan di drop dari model. Berdasarkan tabel hasil pengujian validitas disimpulkan bahwa semua indikator telah memiliki nilai loading factor di atas 0.50 dan dapat dinyatakan semua indikator tersebut sudah memenuhi kriteria convergent validity. 
Dari hasil uji discriminant validity dapat dilihat bahwa beberapa nilai loading factor untuk setiap indikator dari masing-masing variabel laten sudah memiliki nilai loading factor yang paling besar dibanding nilai loading jika dihubungkan dengan variabel laten lainnya. Hal ini berarti bahwa setiap variabel laten memiliki discriminant validity yang baik dimana beberapa variabel laten masih memiliki pengukur yang berkorelasi tinggi dengan konstruk lainnya (Ghozali, 2014).

Tabel 1. Uji Discriminant Validity (Fornell Larcker)

\begin{tabular}{|c|c|c|c|}
\hline & Citra Merek_Y & Minat Beli_Z & e-WOM_X \\
\hline Citra Merek_Y & 0.817 & & \\
\hline Minat Beli_Z & 0.557 & 0.829 & \\
\hline e-WOM_X & 0.452 & 0.612 & 0.758 \\
\hline
\end{tabular}

Sumber : Output PLS, 2019

Sedangkan hasil pengujian disimpulkan bahwa akar kuadrat dari Average Variance Extracted (AVE) untuk setiap konstruk lebih besar daripada korelasi antara konstruk yang satu dengan konstruk yang lainnya dalam model. Dari nilai AVE tersebut, maka konstruk dalam model yang diestimasi memenuhi kriteria discriminant validity (Ghozali, 2014).

Tabel 2. Average Variance Extracted

\begin{tabular}{|c|c|}
\hline & Average Variance Extracted (AVE) \\
\hline e-WOM_X & 0.575 \\
\hline Citra Merek_Y & 0.667 \\
\hline Minat Beli_Z & 0.688 \\
\hline
\end{tabular}

Sumber : Output PLS, 2019

Langkah terakhir pengujian model outer adalah dengan melakukan pengujian composite reliability. Dari hasil pengujian composite reliability dan cronbach alpha dapat diketahui bahwa hasil pengujian composite reliability dan cronbach alpha menunjukan nilai yang memuaskan, yaitu semua variabel laten telah reliabel karena seluruh nilai variabel laten memiliki nilai composite reliability dan cronbach alpha $\geq 0,70$. Dan dapat disimpulkan bahwa, kuesioner yang digunakan sebagai alat penelitian ini telah andal atau konsisten (Ghozali, 2014).

Tabel 3. Tabel Cronbach's Alpha dan Composite Reliability 


\begin{tabular}{|c|c|c|}
\hline & Cronbach's Alpha & Composite Reliability \\
\hline e-WOM_X & 0.892 & 0.914 \\
\hline Citra Merek_Y & 0.751 & 0.857 \\
\hline Minat Beli_Z & 0.882 & 0.916 \\
\hline
\end{tabular}

Sumber : Output PLS, 2019

\subsection{Pengujian Model Struktural/Uji Hipotesis (Inner Model)}

Pengujian inner model adalah pengembangan model berbasis konsep dan teori dalam rangka menganalisis hubungan variabel eksogen dan endogen telah dijabarkan dalam kerangka konseptual. Tahapan pengujian terhadap model structural (uji hipotesis) dilakukan dengan menghitung Nilai $R$ square serta goodness of fit model.

Dari pengujian R-square dapat diketahui bahwa nilai R-square pada variabel endogen Minat Beli sebesar 0.473 yang berarti variabilitas Minat Beli (MB) yang dapat dijelaskan oleh kedua variabel dalam model yaitu Electronic Word of Mouth dan Citra Merek sebesar 47.3\% sedangkan 52.7\% dijelaskan oleh variabel lain yang tidak diteliti dalam model ini. Kemudian nilai R-square pada variabel endogen Citra Merek sebesar 0.205 atau 20.5\% dipengaruhi oleh variabel Electronic Word of Mouth sedangkan 79.5\% dijelaskan oleh variabel lain yang tidak diteliti dalam model ini.

Sedangkan hasil perhitungan goodness of fit menggunakan rumus Q2 memperlihatkan nilai predictive relevance sebesar $0.205>0$ dan $0.473>0$. Hal itu berarti bahwa $20.5 \%$ variasi pada variabel Citra Merek dan untuk nilai 47.3\% variasi pada variabel Minat Beli (dependent variable) dijelaskan oleh variabel-variabel yang digunakan, dengan demikian model dikatakan layak untuk memiliki nilai prediktif yang relevan (Ghozali, 2014).

\subsection{Pengujian Hipotesis (Estimasi Koefisien Jalur)}

Nilai estimasi untuk hubungan jalur dalam model struktural harus signifikan. Nilai signifikan ini dapat diperoleh dengan prosedur boostrapping (Ghozali, 2014). Melihat signifikansi pada hipotesis dengan melihat nilai koefisien parameter dan nilai signifikansi t statistik pada algorithm boostrapping report. Untuk mengetahui signifikan atau tidak signifikan dilihat dari t-tabel pada alpha $0,01(1 \%)=2,69$. Kemudian t-tabe dibandingkan dengan t-hitung (t-statistik) (Ghozali, 2014).

Pada penelitian ini dibentuk tiga hipotesis sebagai hasil dari kajian teori yang telah dipaparkan sebelumnya yaitu:

$\mathrm{H}_{1}$ : Electronic Word of Mouth berpengaruh terhadap citra merek

$\mathrm{H}_{2}$ : Citra merek berpengaruh terhadap minat beli

$\mathrm{H}_{3}$ : Electronic Word of Mouth berpengaruh terhadap minat beli 

berikut:

Tabel 4 Hasil Pengujian Hipotesis

\begin{tabular}{|c|c|c|c|c|c|}
\hline & $\begin{array}{c}\text { Original } \\
\text { Sample } \\
\text { (0) }\end{array}$ & $\begin{array}{c}\text { Sample } \\
\text { Mean (M) }\end{array}$ & $\begin{array}{c}\text { Standard } \\
\text { Deviation } \\
\text { (STDEV) }\end{array}$ & $\begin{array}{c}\text { T Statistics } \\
(\mid \mathbf{O} / \text { STDEV|) }\end{array}$ & P Values \\
\hline $\begin{array}{c}\text { e-WOM_X ->Citra } \\
\text { Merek_Y }\end{array}$ & 0.452 & 0.458 & 0.051 & 8.815 & 0.000 \\
\hline $\begin{array}{c}\text { Citra Merek_Y -> } \\
\text { Minat Beli_Z }\end{array}$ & 0.353 & 0.350 & 0.060 & 5.863 & 0.000 \\
\hline $\begin{array}{c}\text { e-WOM_X_> Minat } \\
\text { Beli_Z }\end{array}$ & 0.452 & 0.458 & 0.059 & 7.644 & 0.000 \\
\hline
\end{tabular}

Output PLS, 2019

\section{$3.5 \quad$ Uji Hipotesis}

1. Electronic word of mouth (e-WOM) berpengaruh secara signifikan terhadap citra merek. Karena, T statistic $>$ T tabel $(8.815>2.69)$ dan hipotesis diterima, yang menyatakan bahwa apabila tanggapan atau pernyataan seseorang baik itu positif maupun negatif di media sosial terhadap rumah makan Se'i Sapi Lamalera berpengaruh terhadap citra dari rumah makan Se'i Sapi Lamalera di mata konsumen.

2. Citra merek berpengaruh secara signifikan terhadap minat beli. Karena, T statistic $>\mathrm{T}$ tabel (5.863 > 2.69) dan hipotesis diterima, yang dapat disimpulkan bahwa citra dari suatu merek atau produk dapat menimbulkan minat beli pada konsumen.

3. Electronic word of mouth $(e-W O M)$ berpengaruh secara signifikan terhadap minat beli. Karena, T statistic $>$ T tabel $(7.644>2.69)$ dan hipotesis diterima, yang menyatakan bahwa apabila tanggapan atau pernyataan seseorang baik itu positif maupun negatif di media sosial terhadap rumah makan Se'i Sapi Lamalera berpengaruh terhadap minat beli di rumah makan Se'i Sapi Lamalera.

Berikut ini ditampilkan gambaran hasil bootstrapping yang dilakukan dengan menggunakan WARP PLS sebagai acuan pengujian hipotesis adalah sbb: 


\section{Gambar 2. Hasil Bootstrapping}

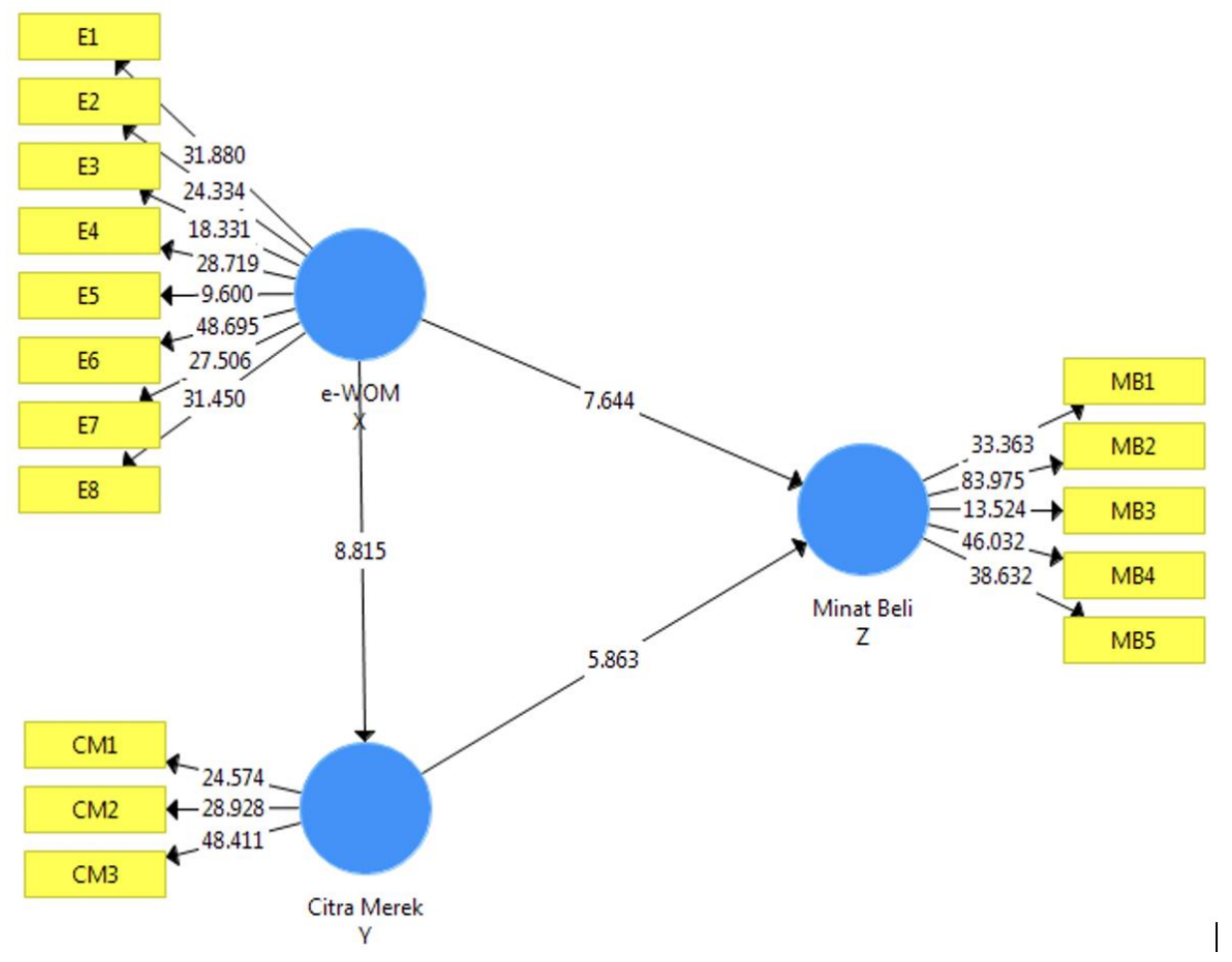

Gambar 2. Hasil Bootstrapping

Sumber: Data Diolah, 2019

\subsection{Pengaruh Electronic Word of Mouth terhadap Citra Merek}

Berdasarkan uji hipotesis pada penelitian ini, menunjukan hasil bahwa Electronic Word of Mouth ( $e$-WOM) berpengaruh positif dan signifikan terhadap citra merek dengan nilai T statistic 8.815 dan nilai dari $\mathrm{P}$ value 0.000 dimana nilai $\mathrm{P}$ value tidak lebih besar dari nilai 0.01 . Hasil penelitian sejalan dengan penelitian yang dilakukan oleh Khan dan Ali (2017) yang menyatakan bahwa $e$-WOM memiliki pengaruh yang besar terhadap citra merek. Pernyataan tersebut menunjukkan bahwa hasil penelitian saat ini mengindikasikan bahwa pendapat atau pernyataan seseorang baik itu positif ataupun negatif dapat mempengaruhi citra dari suatu produk ataupun perusahaan (Se'i Sapi Lamalera), dengan tiga dimensi dari e-WOM diantaranya yaitu, Intensity, Valence of Opinion dan Content.

Berdasarkan nilai mean tertinggi pada e-WOM yaitu indikator $e$-WOM dengan bentuk pernyataan "Saya mencari terlebih dahulu media sosial atau website resmi yang dikelola oleh Se'i Sapi Lamalera" serta pernyataan "Saya tertarik saat influencer atau food blogger merekomendasikan Se'i Sapi Lamalera" dengan nilai mean terbesar yaitu (3.93) menunjukkan bahwa dari 307 responden dalam penelitian ini merasa setuju dengan pernyataan tersebut bahwa responden mencari informasi tentang Se'i Sapi Lamalera melalui media sosial dan website resmi yang dikelola oleh pihak Se'i Sapi Lamalera dan responden merasa setuju bahwa artikel atau pernyataan rekomendasi dari influencer dan food blogger membuat mereka tertarik pada Se'i Sapi Lamalera.. 


\subsection{Pengaruh Citra Merek Terhadap Minat Beli}

Berdasarkan hasil uji hipotesis, penelitian ini menunjukan hasil bahwa citra merek berpengaruh positif signifikan terhadap Minat Beli dengan nilai T statistic 5.863 dan nilai dari P value 0.000 dimana nilai P value tidak lebih besar dari nilai 0.01. Hasil penelitian ini memperkuat penelitian yang telah dilakukan oleh Satria dan Sidharta (2017) yang menunjukan bahwa citra merek berpengaruh secara signifikan minat beli dan berarti citra merek merupakan faktor penting yang berpengaruh terhadap minat beli. Hal ini berdasarkan nilai rata-rata terbesar indikator citra merek yang memiliki pernyataan “Se'i Sapi Lamalera adalah rumah makan yang menyediakan olahan Se'i khas Kupang yang halal untuk dikonsumsi" artinya, bahwa sebagian besar responden setuju bahwa Se'i Sapi Lamalera menyediakan olahan Se'i yang halal, mayoritas responden mengisi jawaban sangat setuju.

\subsection{Pengaruh Electronic Word of Mouth Terhadap Minat Beli}

Berdasarkan uji hipotesis yang telah dilakukan, penelitian ini menunjukan bahwa $e$-WOM berpengaruh positif signifikan terhadap minat beli dengan nilai t statistic 7.644 dan nilai dari P value 0.000 dimana nilai P value tidak lebih besar dari nilai 0.01 . Hasil penelitian ini memperkuat penelitian yang dilakukan oleh Laksmi dan Oktafani (2016) menunjukkan bahwa e-WOM berpengaruh secara positif terhadap minat beli. Penelitian lain yang menyatakan pernyataan serupa adalah penelitian dari Putri dan Sastika (2016) yang menyatakan terdapat pengaruh yang diberikan oleh e-WOM terhadap Minat Beli, pendapat atau pernyataan seseorang terhadap suatu produk atau jasa dapat menimbulkan minat untuk membeli suatu produk atau jasa tersebut.

Pada penelitian ini salah satu pernyataan yang menarik adalah pernyataan "Saya tertarik untuk mengetahui harga dan kualitas produk di Se'i Sapi Lamalera”. Artinya, bahwa sebagian besar responden berminat untuk mengetahui tentang harga dan kualitas produk yang ditawarkan di Se'i Sapi Lamalera.

\section{IMPLIKASI MANAJERIAL}

1. Pada variable Electronic Word of Mouth ( $e$-WOM), nilai jawaban responden dengan mean yang paling kecil adalah indikator E9 dengan pernyataan "Se'i Sapi Lamalera aktif dalam memberikan informasi promo terkini dalam akun media sosialnya atau website yang dikelola" dan indikator kedua paling kecil adalah E7 dengan pernyataan "Saya tertarik saat melihat unggahan di media sosial maupun website tentang Se'i Sapi Lamalera" yang artinya, sebagian besar responden merasa bahwa Se'i Sapi Lamalera kurang aktif dalam memberikan informasi mengenai promo di media sosial maupun Instagram dan sebagian besar responden merasa kurang tertarik dengan unggahan di media sosial maupun website tentang Se'i Sapi Lamalera. Saran yang dapat dijadikan bahan pertimbangan untuk pihak Se'i Sapi Lamalera adalah dengan memperbanyak promosi terhadap produk setidaknya satu kali dalam sebulan selain baik di media sosial instagram, facebook maupun situs web yang dikelola itu pihak Se'i Sapi Lamalera disarankan untuk memperbaiki konten yang di unggah baik di media sosial instagram, facebook maupun situs web yang dikelola, dengan kualitas pengambilan gambar atau photography dengan kualitas yang tinggi dan pemilihan komposisi warna yang baik agar desain nampak menarik untuk dipandang.

2. Pada variabel Citra Merek, nilai jawaban responden dengan mean yang paling kecil adalah indicator CM2 dengan pernyataan "Produk yang ditawarkan Se'i Sapi Lamalera berkualitas 
dan bervariasi” yang artinya, sebagian besar responden merasa bahwa produk yang ditawarkan oleh Se'i Sapi Lamalera kurang berkualitas dan variasi produknya masih dirasa sedikit. Saran yang dapat dijadikan bahan pertimbangan untuk pihak Se'i Sapi Lamalera adalah dengan meningkatkan lagi kualitas produknya seperti pemilihan bahan baku yang lebih segar, memperbaiki tampilan atau presentasi makanan pada konsumen (packaging) dan menambahkan menu khas Kupang lainnya seperti sup brenebon, jagung catemak dan lain sebagainya.

\section{SIMPULAN}

Berdasarkan pemaparan diatas berikut ini adalah kesimpulan dari penelitian ini, sbb:

1. Dari analisis bab sebelumnya dapat diketahui bahwa variabel Electronic Word of Mouth $(e-W O M)$ berpengaruh secara positif dan signifikan terhadap Citra Merek yang berarti $\mathrm{H}_{1}$ diterima. Jadi dapat disimpulkan bahwa pesan atau informasi yang didapat oleh seseorang terhadap Se'i Sapi Lamalera dapat mempengaruhi persepsi dan keyakinan terhadap rumah makan Se'i Sapi Lamalera.

2. Dari analisis bab sebelumnya dapat diketahui bahwa variabel Citra Merek berpengaruh secara positif dan signifikan terhadap Minat Beli yang berarti $\mathrm{H}_{2}$ diterima. Jadi dapat disimpulkan persepsi dan keyakinan seseorang terhadap rumah makan Se'i Sapi Lamalera dapat menimbulkan minat untuk membeli produk yang ditawarkan oleh Se'i Sapi Lamalera.

3. Dari analisis bab sebelumnya dapat diketahui bahwa variabel Electronic Word of Mouth (e-WOM) berpengaruh secara positif dan signifikan terhadap minat beli yang berarti $\mathrm{H}_{3}$ diterima. Jadi dapat disimpulkan bahwa pesan atau informasi yang didapat oleh seseorang terhadap Se'i Sapi Lamalera dapat menimbulkan minat untuk membeli produk yang ditawarkan oleh Se'i Sapi Lamalera.

4. Dari analisis bab sebelumnya, dapat disimpulkan bahwa lebih efektif membangun minat beli melalui electronic word of mouth secara langsung dibandingkan membangun citra merek terlebih dahulu.

\section{SARAN}

Bagi penelitian selanjutnya, dilihat dari hasil uji $R$-square hanya memperoleh sebesar $47.3 \%$ pengaruh Electronic Word of Mouth (e-WOM) dan Citra Merek terhadap Minat Beli di Se'i Sapi Lamalera. Saran yang dapat dipertimbangkan untuk penelitian selanjutnya agar dapat meneliti 52.7\% faktor lainnya yang dapat mempengaruhi minat beli. Selain itu menambahkan indikator kapasitas pada variabel citra merek dalam teori corporate image.

Penelitian selanjutnys dapat juga dilakukan pada skala yang lebih luas serta industri yang berbeda. Penelitian ini diharapkan untuk dapat menjadi bahan pertimbangan untuk mengelola platform digital seperti media sosial maupun situs web yang dikelola dan untuk mengelola pendapat positif maupun negatif di platform digital. Selain itu, agar dapat menjadi bahan pertimbangan untuk mengelola unggahan di media sosial maupun situs web dengan tepat dan mengunggah konten yang menarik untuk diunggah supaya dapat menarik perhatian audiens di media sosial maupun di situs 
web. Selain itu perusahaan diharapkan untuk tetap memperhatikan hal-hal penting lainnya. Seperti melakukan promosi dan memperluas pangsa pasar. 


\section{DAFTAR PUSTAKA}

Badan Pusat Statistik Kota Bandung. (2016, Juli 15). Kota Bandung Dalam Angka 2016. Diunduh dari www.bandungkota.bps.go.id:

https://bandungkota.bps.go.id/publication/2016/07/15/e1f27d4d9f7cadf8fc33a97a/kotabandung-dalam-angka-2016.html

Ghozali, I. (2014). Structural Equation Modeling Teori, Konsep dan Aplikasi Dengan Program Partial Least Square. Semarang: Badan Penerbit Universitas Diponegoro.

GoMuslim. (2016, Oktober 31). Pemerintah Bandung Targetkan Tahun 2017 Seluruh Restoran di Kota Kembang Bersertifikat Halal. Diunduh dari www.gomuslim.co.id: Pemerintah Bandung Targetkan Tahun 2017 Seluruh Restoran di Kota Kembang Bersertifikat Halal

Hong, I. (2016, Oktober 2016). Pemkot Bandung Imbau Seluruh Restoran Urus Sertifikat Halal. Diunduh dari www.halhalal.com: http://www.halhalal.com/pemkot-bandung-himbauseluruh-restoran-urus-sertifikat-halal/

Kamtarin, M. (2012). The Effect of Electronic Word of Mouth, Trust and.

Khan, K., \& Ali, M. (2017). Impact of Electronic Word of Mouth on Consumer Purchase Intention in Footwear Industry of Pakistan.

Kotler, P., \& Keller, K. L. (2012). Marketing Management, 14th Edition. Pearson Education.

Laksmi, A. A., \& Oktafani, F. (2016). Pengaruh Electronic Word Of Mouth (EWOM) Terhadap Minat Beli Followers Instagram Pada Warunk Upnormal.

Putri, H., \& Sastika, W. (2016). Pengaruh Electronic Word of Mouth (e-WOM) Melalui Twitter Terhadap Minat Beli Konsumen Pada Steak Ranjang Bandung.

Samuel, H., \& Lianto, A. S. (2014). Analisis eWOM, Brand Image, Brand Trust Dan Minat Beli. Jurnal Manajemen Pemasaran, Vol. 8, No. 2, Oktober 2014.

Satria, D. A., \& Sidharta, H. (2017). Pengaruh Citra Merek dan Kualitas Produk Terhadap Minat Beli Konsumen Porkball.

Se'i Sapi Lamalera. (2018, September). Facebook. Diunduh dari www.facebook.com/seisapilamalera

Se'i Sapi Lamalera. (2018, September). Instagram Se'i Sapi Lamalera. Diunduh dari www.instagram.com/seisapilamalera.

Se'i Sapi Lamalera. (2018, September). Introduction. Diunduh dari www.seilamalera.com.

Se'i Sapi Lamalera. (2018). Jumlah Bon Transaksi Se'i Sapi Lamalera Bandung 2017-2018. Bandung.

Thurau, T. H., Gwinner, K. P., Walsh, G., \& Gremler, D. D. (2004). Journal of Interactive Marketing. 